\title{
Unicornuate uteri associated with contralateral renal agenesis and ovarian anomalies
}

\section{Kontralateral renal agenezis ve over anomalileri ile birlikte tek boynuzlu uterus}

\author{
Albana Cerekja ${ }^{1}$, Kathleen Comalli Dillon ${ }^{2}$, Eva Racanska ${ }^{3}$, Juan Piazze ${ }^{4}$ \\ 'Ultrasound Service, Radiology Department, Asl Roma B, Italy \\ ${ }^{2}$ Comalli Medical Writing, Petaluma, California, USA \\ 3inner Vision Women's Ultrasound, Nashville-tennessee, USA \\ ${ }^{4}$ Ultrasound Service, Ospedale Di Ceprano, Frosinone, Italy
}

\section{Abstract}

Our findings regarding two cases of unicornuate uterus validate that conventional transvaginal ultrasound is helpful in diagnosing uterine anomalies. Moreover, anomalies of the urinary system and the contralateral ovary should always be considered.

(J Turkish-German Gynecol Assoc 2011; 12: 189-91)

Key words: Unicornuate uterus, renal agenesis, ovarian anomalies

Received: 13 August, 2010

Accepted: 19 September, 2010
Özet

Tek boynuzlu uterusu olan iki olguyla ilgili bulgularımız, konvansiyonel transvajinal ultrasonun uterin anomalilerin tanısında yardımcı olduğunu doğrulamıştır. Bunun yanı sıra, üriner sistemin ve kontralateral overin anomalileri daima göz önünde bulundurulmalıdır.

(J Turkish-German Gynecol Assoc 2011; 12: 189-91)

Anahtar kelimeler: Tek boynuzlu uterus, renal agenezis, over anomalileri

Geliş Tarihi: 13 Ağustos 2010

Kabul Tarihi: 19 Eylül 2010

\section{Introduction}

The female reproductive system originates with the Müllerian ducts which, during embryogenesis, fuse to create the uterine tubes, uterus, and the upper two-thirds of the vagina. If one of the ducts does not develop, only one Müllerian duct contributes to uterine development. This so-called hemi-uterus has a single horn linked to the ipsilateral uterine tube facing its ovary. A unicornuate uterus has a single cervix and vagina (uterus unicornus unicollis, vagina simplex). On the opposite side, the contralateral Müllerian duct may undergo some development. In such a case, a rudimentary horn is present, which may or may not be connected to the hemi-uterus or to the ispilateral tube. Furthermore, the rudimentary horn may or may not have an endometrial cavity. When a functioning endometrium is present, haematometra and haematosalpinx with dysmenorrhoea soon after menarche can be observed. A blastocyst may also implant in a communicating or a noncommunicating cavitary rudimentary horn; the latter is only possible via transperitoneal migration of sperm. Since uterine rupture can occur, surgical resection of the rudimentary horn is indicated to avoid this life-threatening condition (1). Associated defects may involve the renal system (kidneys, urethra) due to their close embryological interactions, and, less commonly, the skeleton. Unicornuate uterus is much less common than other uterine malformations, with an estimated occurrence of about $1 / 4,000$ (2). In the latest ASRM (American Society for Reproductive Medicine) (3) system for classification of uterine anomalies, formalized in 1988 and currently in use, the unicornuate uterus is classified as class II, and is subdivided into: II a: with communicating rudimentary horn

II b: with noncommunicating rudimentary horn

II c: rudimentary horn without cavity

II d: without any rudimentary horn - also called true unicornuate uterus.

Regarding associated renal anomalies, the literature reports that $70-89 \%$ of patients with unilateral renal agenesis may have associated genital anomalies (4). On the other hand, many authors have investigated the presence of urinary anomalies each time a unicornuate uterus is diagnosed. In a study by Fedele et al. (5), $40.5 \%$ of the patients with a unicornuate uterus presented with urinary tract anomalies such as renal agenesis, ectopic kidney, horseshoe kidney, double renal pelvis, and/or unilateral medullary sponge kidney. Rolen et al. (6) found $67 \%$ of patients with unicornuate uterus had ipsilateral renal agenesis, 13\% of them having a pelvic kidney. Furthermore, upon detection of a unicornuate uterus, anomalies of the contralateral ovary must be looked for. The entirely separate origin of the ovaries from the gonadal ridges explains the infrequent association of uterovaginal anomalies with ovarian anomalies (7). However, reports of ovarian anomalies in cases of unicornuate uteri are not rare. The ovary may be absent (8-10) or undescended,

Address for Correspondence: Dr. Juan Piazze, V. Tuscolana, 620 CAP 00181 Rome-Italy

Phone: +393397843942 Fax: +390639387446 e.mail: jjpiazze2000@hotmail.com

(C) Copyright 2011 by the Turkish-German Gynecological Education and Research Foundation - Available on-line at www.jtgga.org doi:10.5152/jtgga.2011.44 
with attachment of the upper pole to an area above the level of the common iliac vessels (11). Ectopic ovaries are characterized by their attachment to an area above the level of the common iliac vessels. Dabirashrafi et al. (12) found that the incidence of ovarian malposition is higher in patients with congenital uterine anomalies than in a control group. This is especially true when the uterus is absent or only partially present. The incidence is reported to be as high as $42 \%$ in cases of unicornuate uterus (13). Despite the well-known association of ectopic ovaries with a unicornuate uterus, ectopic ovaries are reported only sporadically, suggesting the possibility that many cases go unrecognized. The contralateral ovary may also have some other pathology such as endometriosis, perhaps due to retrograde menstrual blood in case of the presence of a cavitated rudimentary horn (14). We present two cases of unicornuate uteri, one of which was associated with agenesis of the contralateral ovary and kidney and the other associated with a contralateral undescended ovary and renal agenesis.

\section{Case Reports}

\section{Patient 1}

A 19-year-old woman (G0P0) was asked to return for a transvaginal examination because "the left ovary was not visualized" during a routine transabdominal scan.

Her past medical history included a corrected lateral sacral congenital lipomyelomeningocele. The patient had a neurogenic bladder. Furthermore, left renal agenesis was reported.

During the 2D transvaginal examination, the uterus was found to be markedly deviated to the right; a perfect transverse section at the fundal level could not be obtained because of inability to follow the interstitial portion of the left uterine tube at the uterine cornu. Uterine dimensions were approximately those of a normal nulliparous woman, that is, longitudinal diameter $81 \mathrm{~mm}$, AP diameter $28 \mathrm{~mm}$, and transverse diameter $32 \mathrm{~mm}$, slightly narrow. Endometrial thickness and echostructure were concordant with the menstrual phase.

The right ovary was visualized cranial to the fundus; an anechoic structure was present consistent with a simple follicle corresponding to the menstrual phase. The left ovary was not visualized even on searching transabdominally, attempting to verify an extremely high adnexal position. No adnexal mass attributable to a rudimentary horn was visualized.

The patient was referred to Radiology where an MRI was performed, confirming the diagnosis of right type D unicornuate uterus and agenesis of the left ovary and left kidney.

\section{Patient 2}

A 34-year-old nulliparous woman, G1P0, was referred to the ultrasound service for a routine examination. Her past medical history included excision of the ocular bulbus performed at age 9 for left ocular retinoblastoma (the patient wore glasses with an opaque left lens). A previous spontaneous abortion, with no subsequent uterine cavity revision, was also reported.

During 2D transvaginal examination, the uterus was found to be deviated to the right but less markedly than in case 1 . Once more, a perfect transverse section at the fundal level could not be obtained. Uterine dimensions were approximately those of a normal nulliparous woman, that is, longitudinal diameter 78 $\mathrm{mm}$, AP diameter $34 \mathrm{~mm}$, and transverse diameter at $40 \mathrm{~mm}$. The right ovary was visualized and no adnexal mass attributable to a rudimentary horn was visualized.

Then, using a transabdominal approach, the left ovary containing two small follicular cysts was visualized, positioned very cranially in the left abdomen.

We searched for renal anomalies and found no visualization of the left kidney. The right kidney appeared normal, with a longitudinal diameter longer than normal $(138 \mathrm{~mm})$, denoting compensatory hypertrophy.

The patient was referred to Radiology. Hysterosalpingography and MRI were performed, confirming the diagnosis of right type D unicornuate uterus, undescended left ovary, and left renal agenesis.

\section{Discussion}

Women with this condition may be asymptomatic and unaware of having a unicornuate uterus; normal pregnancy may occur. In a review of the literature, Reichman et al. analyzed the data on pregnancy outcomes of 290 women with a unicornuate uterus. 175 women conceived, for a total of 468 pregnancies. They found that about $50 \%$ of patients delivered a live neonate. The incidence of ectopic pregnancy was $2.7 \%$; of miscarriage $34 \%$; and of preterm delivery $20 \%$; while the incidence of intrauterine demise was $10 \%$ (2). Thus, patients with a unicornuate uterus are at elevated risk for pregnancy loss and obstetrical complications.

Transvaginal ultrasonography is an important diagnostic tool for the study of uterine anomalies (15). The transvaginal probe allows detailed study of the uterus through combined transverse, coronal and longitudinal planes and an accurate study of the adnexa. It is an important instrument in the diagnosis of unicornuate uteri as well. In these cases, transabdominal and transvaginal scanning complementing each other aids in the diagnosis of associated renal and ovarian anomalies. In fact, in cases of unicornuate uterus, renal contralateral agenesis is common, as are contralateral ovarian anomalies such as agenesis or undescended ovary. It seems that a right unicornuate uterus is more frequent than a left. Most cases in the literature describe a right unicornuate uterus with left renal agenesis, left ovarian agenesis, or left undescended ovary. The findings of our report also confirm the association between urinary and genital anomalies, suggesting that each time renal agenesis is diagnosed, it is important to look for genital anomalies, and equally, each time a uterine anomaly is suspected, the physician should look for renal anomalies.

Our findings prove that conventional transvaginal sonography is helpful in diagnosing uterine anomalies, but suspicion should be confirmed by other techniques. Furthermore, anomalies of the urinary system and contralateral ovary should be always sought. 


\section{Conflict of interest}

No conflict of interest was declared by the authors.

\section{References}

1. Dhar H. Rupture of non-communicating rudimentary uterine horn pregnancy. J Coll Physicians Surg Pak 2008; 18: 53-4.

2. Reichman D, Laufer MR, Robinson BK. Pregnancy outcomes in unicornuate uteri: a review. Fertil Steril 2008; 91: 1886-94.

3. The American Fertility Society. The American Fertility Society classification of adnexal adhesions, distal tubal occlusions, tubal occlusion secondary to tubal ligation, tubal pregnancies, Müllerian anomalies and intrauterine adhesions. Fertil Steril 1988; 49: 944-55.

4. Amin J, Barakat A. Association of unilateral renal agenesis and genital anomalies. Case Rep Clin Pract Rev 2002; 3: 57-60.

5. Fedele L, Bianchi S, Agnoli B, Tozzi L, Vignali M. Urinary Tract Anomalies Associated with Unicornuate Uterus. J Urol 1996; 155 : 847-8. [CrossRef]

6. Rolen AC, Choquette AJ, Semmens JP. Rudimentary uterine horn: obstetric and gynecologic implications. Obstet Gynecol 1966; 27: 806-13.

7. Thompson JD, Rock JA. Linde's Operative Gynecology, Seventh Edition. J.B. Lippincott Company, Philadelphia, Pennsylvania 1992; 1411
8. Haydardedeoglu B, Simsek E, Kilicdag E, Tarim E, Aslan E, Bagis T. A case of unicornuate uterus with ipsilateral ovarian and renal agenesis. Fertil Steril 2006; 85: 750-4. [CrossRef]

9. Mülayim B, Demirbaşoğlu S, Oral O. Unicornuate uterus and unilateral ovarian agenesis associated with pelvic kidney. Surg Endosc 2003; 17: 161 .

10. Demir B, Guven S, Guvendag Guven ES, Serdar Gunalp G. An incidental finding of unicornuate uterus with unilateral ovarian agenesis during cesarean delivery. Arch Gynecol Obstet 2007; 276: 91-3. [CrossRef]

11. Ombelet W, Grieten M, DeNeubourg P, Verswijvel G, Buekenhout L, Hinoul P, et al. Undescended ovary and unicornuate uterus: Simplified diagnosis by the use of clomiphene citrate ovarian stimulation and magnetic resonance imaging (MRI). Human Reproduction 2003; 18: 858-62. [CrossRef]

12. Dabirashrafi H, Mohammad K, Moghadami-Tabrizi N. Ovarian Malposition in Women With Uterine Anomalies. Obstet Gynecol 1994; 83: 293-4.

13. Ombelet, W, Verswijvel G, de Jonge E. Ectopic Ovary and Unicornuate Uterus. N Engl J Med 2003; 348: 667-8. [CrossRef]

14. Fedele L, Bianchi S, Tozzi L, Vignali M. Anatomic Features of 49 Unicornuate Uteri: Gynecologic and Urologic Findings, Associated Disorders, and Endometrial Patterns. J Gyn Surg 2009; 12: 159-65.

15. Jurkovic D, Gruboeck K, Tailor A, Nicolaides KH. Ultrasound screening for congenital uterine anomalies. Br J Obstet Gynaecol 1997; 104: 1320-1. [CrossRef] 